\title{
ESTUDOS DE TRADUÇÃO E SEMIOLOGIA: AS CONTRIBUIÇÕES DE UMBERTO ECO
}

\author{
Fabiano Bruno Gonçalves*
}

\begin{abstract}
RESUMO: By exposing the reflections on interpretation and translation by the Italian semiologist and novelist Umberto Eco, we intend to make it clear that his ideas and theories are of great value to any current reflection on translation - mainly literary translation. Albeit chiefly based upon linguistics, the semiologist's ideas are loaded with a wide range of knowledge from many fields, which only contributes to a firmly based "theory" of translation.
\end{abstract}

PALAVRAS-CHAVE: Estudos de Tradução. Semiologia. Literatura Comparada.

Ao longo da história dos estudos de tradução, tem sido praxe o estabelecimento de subdivisões das principais orientações seguidas pelos críticos e teóricosí; com o passar do tempo, percebeu-se que muitas dessas subdivisões compartilhavam de ditames e crenças essencialmente semelhantes, podendo alguns grupos ser abarcados dentro de um mesmo quadro. À medida que o tempo foi passando, mais e mais "novas" teorias foram surgindo. Atualmente, ao olharmos para trás, podemos perceber que, à exceção de pequenas diferenças, podemse dividir as teorias e orientações tradutórias em dois grandes grupos. Solange Mittmann ii aponta essas duas principais perspectivas nos estudos de tradução: perspectiva tradicional e perspectiva contestadora. Em cada uma dessas, a autora seleciona elementos representativos tanto do cenário nacional quanto do estrangeiro, eis que podem ser utilizados como ícones das perspectivas que representam. Na perspectiva tradicional, representada no exterior por Eugene A. Nida, e no Brasil por Erwin Theodor e Paulo Rónai, Mittmann identifica idéias de resgate e decodificação do pensamento autoral e recodificação do mesmo na outra língua, sendo que o texto e a língua eram os elementos cogitados, ignorando-se, via de regra, as condições de produção da tradução - o que atualmente é chamado de contexto, em geral. Já na perspectiva contestadora, representada por Francis H. Aubert e Rosemary Arrojo no Brasil, e por Lawrence Venuti e Theo Hermans no exterior, a autora identifica uma contestação às concepções tradicionais de tradução, hoje com pouca credibilidade, na qual os elementos mais precípuos da contestação perfazem a defesa de que (i) o léxico não é invólucro de significados imutáveis e não passíveis de interferência, (ii) o texto é invariavelmente interpretado tanto pelo tradutor como pelo leitor, sendo, por conseguinte, interferido e, por fim, (iii) o tradutor tem papel ativo, transformador, estando a sua voz presente no seu produto.

A teoria da tradução atual tem sido tão exaustivamente explorada com base nessa perspectiva contestadora, fortemente amparada na filosofia (hermenêutica e desconstrucionismo, basicamente), que parece até ter-se exaurido: parece que, numa busca pelo atual, pelo novo, pelo inovador, não resta muito aos pesquisadores, a não ser recorrer à interdisciplinaridade - a aproximação com a psicanálise, particularmente a lacaniana, é comum atualmente.

Com essa introdução, queremos chegar ao seguinte ponto: a característica cíclica dos estudos de tradução. A perspectiva tradicional era fortemente amparada pela lingüística, viés que, na literatura comparada, é visto, com freqüência, como uma visão cientificista. É considerada uma abordagem dura, inflexível, com reivindicações quase tão peremptórias quanto as das ciências exatas, excluindo quase que de todo a presença humana no procedimento tradutório. É interessante notar, no entanto, que, um dos representantes nacionais da perspectiva contestadora é amparado pela lingüística, o que não significa que desconsidere a interferência humana no processo. Falamos de Francis Henrik Aubert. A seguir, exporemos as idéias de Umberto Eco acerca da tradução. Semiólogo e romancista, Eco é uma autoridade no tocante às questões de significação e interpretação. Um dos maiores intelectuais da atualidade, tem experiência tanto ativa (traduzindo) quanto passiva (sendo traduzido) de tradução. Amparando-se substancialmente na sua área de concentração, suas reflexões são, a nosso ver, as mais completas da atualidade. Comecemos por expor sua teoria da interpretação, tão importante para compreender o processo tradutório.

\section{A TEORIA DA INTERPRETAÇÃO DE UMBERTO ECO}

Conforme já dissemos, Eco apresenta, em nossa opinião, as reflexões mais completas, abrangentes no que tange à tradução. Não se deve, de maneira alguma, pensar que abrangente signifique raso. Eco apresenta teorias

\footnotetext{
* Fabiano Bruno Gonçalves é mestrando em Literatura Comparada no Programa de Pós-Graduação em Letras da Universidade Federal do Rio Grande do Sul.
} 
extremamente bem fundamentadas e, a partir da leitura dessas, é possível estabelecer uma maneira satisfatória de interpretar textos através do equilíbrio no uso de seus modelos. Eco tem dedicado numerosos volumes às questões de interpretação das obras de arte, o que, logicamente, inclui as literárias. Para os propósitos deste trabalho, no entanto, julgou-se desnecessário um levantamento exaustivo de sua produção teórica, limitando-nos à exposição que segue. Justificamos nossa escolha porque, ao longo de toda a sua obra, há constantes retomadas dos temas que aborda, na comparação de um livro com outro. Além disso, há volumes centrados em assuntos que não vêm ao caso para os nossos propósitos. As obras que compõem o cerne de sua teoria da interpretação são Obra aberta $^{\text {iii }}$ e, principalmente, Lector in fabula $a^{\mathrm{iv}}$ e Os limites da interpretaçãov. Uma síntese de suas idéias pode ser conferida na seguinte citação do texto "Sobre algumas funções da literatura"vi.

A leitura de obras literárias nos obriga a um exercício de fidelidade e de respeito na liberdade da interpretação. Há uma perigosa heresia crítica, típica de nossos dias, para a qual de uma obra literária pode-se fazer o que se queira, nela lendo aquilo que nossos mais incontroláveis impulsos nos sugerirem. Não é verdade. As obras literárias nos convidam à liberdade de interpretação, pois propõem um discurso como muitos planos de leitura e nos colocam diante das ambigüidades, da linguagem e da vida. (ECO, 2003b, p.12)

Parece que $a$ palavra-chave do pensamento de Eco é "limite" - algo avesso ao desconstrucionismo. Segundo exemplos do mesmo texto citado, não se pode dizer que Sherlock Holmes é casado, pois não há, na obra de Sir Arthur Conan Doyle, nenhum indício para crê-lo. Clark Kent é o Super-Homem, assim como Bruce Wayne é o Batman: todos aqueles que já leram os respectivos quadrinhos sabem dessas verdades. Segundo Eco, essas são as chamadas "verdades hermenêuticas": não há como abandonarmo-nos a derivas interpretativas. A obra é aberta e dela pode-se fazer leituras infindáveis, mas, atentando para algumas marcas no texto, veremos que há elementos que nos limitam.

"O mundo da literatura é um universo no qual é possível fazer testes para estabelecer se um leitor tem o sentido da realidade ou é presa de suas próprias alucinações." (ECO, 2003b, p. 14-15)

Sua estratégia é simples e antiga, tomada de empréstimo de Santo Agostinho, em De doctrina christiana, qual seja a de procurar num texto algo que corrobore ou não a interpretação que fazemos de uma parte (ECO, 2001a, p. 76). Ou seja, o contexto em que um trecho é interpretado é a chave básica para validar ou invalidar a interpretação. Eco critica a propensão clássica a considerar que o correto era "descobrir num texto ou o que seu autor pretendia dizer, ou o que o texto dizia independentemente das intenções de seu autor." (ECO, 2003b, pp. 74-75). No processo de leitura, para que se possa compreender a obra, o leitor a reinventa "num ato de congenialidade com o autor." (ECO, 2003a, p. 41). Em suma: entram em jogo a intenção do autor, aquilo que está no texto, e aquilo que o leitor traz consigo; cada elemento dessa relação tem uma intenção própria. Em relação às intenções envolvidas no processo interpretativo, vale abordar a tricotomia das intentiones proposta por Eco:

- Intentio auctoris: intenção do autor. Embora alguns poucos ainda defendam que essa é recuperável, esse fato é comumente inaceitável. Só é possível levantar hipóteses sobre o que o autor quis dizer com base nos elementos mais explícitos dos dados disponíveis para tanto.

- Intentio operis: intenção da obra. Semelhante à intentio anterior, porém centrada no texto, ou seja, naquilo que o texto oferece ao leitor.

- Intentio lectoris: a contribuição do leitor ao interpretar uma obra. A intenção do leitor é a mais controversa da atualidade, possivelmente devido a superinterpretações das idéias de Jacques Derrida.

Há discordância entre os teóricos em relação às intentiones: Antoine Compagnon ${ }^{\text {vii }}$, por exemplo, discorda da pertinência, até mesmo da possível existência, da intentio operis, sendo essa uma atrelagem retirada da fenomenologia, que relaciona intenção com consciência; visto que um texto não pode ter consciência, não é possível haver algo como uma intentio operis (p. 84).

Quanto mais equilibrado for o uso dessas intenções no processo interpretativo, mais sustentável será a interpretação; quanto mais o interpretante pender para uma em detrimento das outras, menos sustentável será sua interpretação. No desequilíbrio do uso das intentiones, o leitor pode incorrer no que Eco chama de "superinterpretação" ou em "uso do texto". Superinterpretação pode ser definida, a priori, como qualquer vôo imaginativo que não possua um embasamento mais concreto: o leitor atribui ao que lê coisas que na verdade não leu, pois não estavam contidas no texto. Um bom exemplo de superinterpretação, citado no texto "Superinterpretando textos"viii , é a crítica a Gabriele Rossetti ter afirmado que Dante pusera em seu texto uma série de símbolos e práticas típicos das tradições maçônica e rosa-cruz. O fato é que a Comédia foi escrita no século XII, e há registros muito confiáveis de que os primeiros indícios das idéias rosacrucianas datem do século XVII, e as primeiras lojas da maçonaria simbólica surgiram no século XVIII (pp. 64-70).

Semelhantemente à superinterpretação, o caso do "uso de textos" relaciona-se mais proximamente com a intentio lectoris. Um caso ilustrativo citado por Eco em Os limites da interpretação é o trabalho de Maria Bonaparte, que fizera uso dos textos de Poe para extrair inferências da vida particular do escritor, inserindo aqui e acolá informações biográficas extratextuais para lograr seu intento (ECO, 2000, p.14). Isso posto, a interpretação é, ao que nos parece, limitada por uma atenção equilibrada às três intentiones.

Em Lector in fabula, temos que "[...] o texto é uma máquina preguiçosa, que exige do leitor um renhido trabalho cooperativo para preencher espaços de não-dito ou de já-dito que ficaram, por assim dizer, em branco 
[...]". (p. 11) O destinatário atualiza o texto, pois “[t]odo texto quer que alguém o ajude a funcionar". (p. 37) Eco diz que "[...] um texto postula o próprio destinatário como condição indispensável não só da própria capacidade concreta de comunicação, mas também da própria potencialidade significativa". (p. 37)

Lemos em Eco o slogan "A competência do destinatário não é necessariamente a do emitente" (p. 38); a discrepância de competências corrobora ainda mais sua proposta de que o leitor é instado a um trabalho cooperativo. Crê que o destino interpretativo de um texto deva fazer parte de seu mecanismo gerativo; ou seja, o autor forma um "Leitor-Modelo". (p. 39): “[...] a noção de interpretação sempre envolve uma dialética entre estratégia do autor e a resposta do Leitor-Modelo". (p. 43)

Eco define o Leitor-Modelo como segue:

O Leitor-Modelo constitui um conjunto de condições de êxito, textualmente estabelecidas, que dever ser satisfeitas para que um texto seja plenamente atualizado no seu conteúdo potencial. (p. 45)

O Leitor-Modelo, em Eco, é uma estratégia textual, assim como o autor (Autor-Modelo). De modo a explicitar a diferença entre o sujeito de carne e osso e aquele que é tido como estratégia textual, propomos o seguinte quadro:

\begin{tabular}{|l|l||l|}
\cline { 2 - 3 } \multicolumn{1}{c||}{} & EMPÍRICO & MODELO \\
\hline \hline AUTOR & ENTE & ESTRATÉGIA TEXTUAL \\
\hline LEITOR & ENTE & ESTRATÉGIA TEXTUAL \\
\hline
\end{tabular}

Tabela 1: diferença entre ente e estratégia textual no que se refere a autor e leitor.

A diferença fica ainda mais clara quando lemos que "[p]ara realizar-se como Leitor-Modelo, o leitor empírico tem naturalmente deveres 'filológicos', ou seja, tem o dever de recuperar, com a máxima aproximação possível, os códigos do emitente." (p. 47) Ou seja, há determinados caminhos que o leitor enquanto ente físico, de carne e osso (leitor empírico), deve seguir com vistas a ter êxito ao assumir a estratégia textual (LeitorModelo).

No afã de evitar mal-entendidos, Eco propõe que, "[a]ntes de mais nada, como cooperação textual não se deve entender a atualização das intenções do sujeito empírico da enunciação, mas as intenções virtualmente contidas no enunciado." (p. 46)

Num caso de ambigüidade, o autor empírico pode não ter tido a intenção de produzi-la, mas o leitor empírico tem o direito de entendê-la como tal, pois, em sua leitura, o Autor-Modelo inseriu essa possibilidade de interpretação nos elementos textuais - eis um jogo das três intentiones.

O que foi exposto é, em nossa leitura, o âmago da teoria da interpretação de Umberto Eco; a seguir, retornaremos à sua obra, desta vez dedicada à tradução.

\section{AS EXPERIÊNCIAS DE ECO NA TRADUÇÃO}

Eco também enveredou pelas sendas da tradução em um de seus últimos livros, Experiences in translation $^{\text {ix }}$, baseado nas Goggio Public Lectures, que proferiu na Universidade de Toronto, em 1998, traduzidas para o inglês e publicadas em 2001. Sob um olhar semiótico, o âmago das discussões de Eco acerca da tradução não foge muito de seus escritos anteriores: a interpretação é presença ubíqua no livro. Como o próprio autor admite, o texto é teoricamente raso em teoria da tradução; todavia, fornece-nos exemplos valiosos, tanto teóricos quanto práticos.

O primeiro questionamento que nos chama a atenção é sobre “[o] que é um 'sentido' que não corresponde ao significado literal? Esse sentido depende do significado lexical das palavras isoladas ou do significado de uma frase $?^{\mathrm{x}}$ " (2001c, p. 8). Figura aí o tradicional e onipresente questionamento sobre a questão contextual. O autor argumenta que se pode dizer que uma boa tradução não se atém tanto à denotação, mas à conotação das palavras. A palavra conotação é um termo-guarda-chuva utilizado para denominar numerosos sentidos não-literais de uma palavra, de uma frase ou de um texto inteiro. Que palavras, frases e textos comumente carregam mais do que seu sentido literal é um fenômeno usualmente aceito, mas os problemas são (i) quantos sentidos secundários podem ser carregados por uma expressão lingüística, e (ii) quais deles uma tradução deveria preservar a todo custo.xi (p. 9)

Visto que decidimos traduzir não com base no dicionário, mas em todo o contexto situacional e em toda a história das duas literaturas em jogo (p. 13), as conotações fornecidas pelo dicionário podem sofrer redução, bem como acréscimo: o contexto reduz ou amplia os significados de uma unidade do texto. Pode haver uma maior ou menor similaridade entre a unidade da língua do texto "original" e a da língua do texto em tradução, mas a "[s]imilaridade relativa ao significado só pode ser estabelecida através da interpretação, e a tradução é um caso especial de interpretação xii", (p. 13). Eco reforça essa asseveração dizendo que as "[t]raduções não se tratam de tipos (types) lingüísticos, mas sim de ocorrências (tokens) lingüísticas. As traduções não dizem respeito a uma

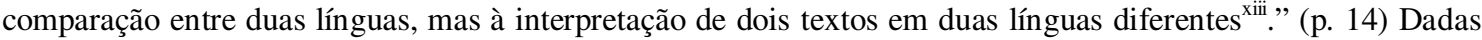


as infindáveis possibilidades de interpretação de um mesmo item, "[i]nterpretar significa apostar no sentido de um texto, entre outras coisas ${ }^{\text {xiv" }}$ (p. 16).

As reflexões de Eco, no livro em questão, são baseadas em suas experiências como autor traduzido, visto que sempre que possível participa das traduções por meio de contatos com seus tradutores, bem como suas experiências de tradutor e professor de tradução intersemiótica na Universidade de Bolonha. Para que avancemos ao fechamento deste texto, observemos um exemplo de cada "situação tradutória" de Eco.

No que concerne a ser traduzido, um exemplo muito rico é o das traduções de $A$ ilha do dia anterior. Eco quer demonstrar, com seus exemplos, quais são as alterações - quando inevitáveis - permissíveis.

É claro que cada texto faz concessões a uma solução diferente e individual. O bom senso sugere que em A ilha do dia anterior os tradutores podem trocar 'Roberto viu um pólipo listrado' [it.:polipi soriani] por 'Roberto viu um pólipo ocelado', mas certamente não têm a permissão de mudar a macroproposição global 'Roberto é um náufrago em um barco abandonado a pouca distância de uma ilha que está além do $180^{\circ}$ meridiano.

Uma primeira hipótese é que se pode mudar o significado de frases isoladas de modo a preservar o significado das microproposições correspondentes. Mas não o sentido das macroproposições globais. Mas e quanto a muitas estórias intermediárias 'rasas' (entre o significado literal de frases isoladas e o significado global de um romance inteiro)? Poder-se-ia decidir, por exemplo, que se um personagem A conta uma piada longa e idiota e se nenhuma tradução literal consegue transpor a idiotice da piada, um tradutor tem a permissão de mudar para outra piada, contanto que fique claro que A conta piadas tolas. É com base nas decisões interpretativas desse tipo que os tradutores jogam o jogo da fidelidade.xv (p. 39)

Em outras palavras, a fidelidade, tradicionalmente considerada como subserviência a praticamente cada letra do "original", é, em Eco, regida por uma interpretação que não fuja à macroproposição, ao texto como um todo, independentemente de haver alguma mudança em níveis menores (microproposição).

Sobre sua experiência como tradutor propriamente dito, vale-se de sua própria tradução de Sylvie, de Gerard de Nerval, um dos textos que mais relê. Fornece-nos um exemplo de um simples vocábulo que é tão fortemente atrelado ao contexto que molda toda a visão do leitor, o que pode operar mudanças, consequentemente, no processo de tradução. A palavra em pauta é chaumière:

(...) o termo francês expressa pelo menos cinco propriedades: uma chaumière é (i) a casa de um camponês, (ii) pequena, (iii) geralmente feita de pedra, (iv) com telhado de colmo, (v) humilde. É impossível dizer isso em italiano em apenas uma palavra, principalmente se é preciso acrescentar, conforme ocorre no capítulo 6 , que a petite chaumière da tia era 'en pietres de grès inegales'. Essa não é uma capanna, que em italiano sugere uma estrutura de madeira. Não é uma casetta por possuir telhado de colmo (ao passo que, em italiano, casetta possui um telhado de telhas, e não é necessariamente uma residência pobre), mas nem mesmo é uma baita, que é uma construção tosca encontrada nas montanhas, um refúgio temporário. Sinto que nem mesmo uma cabana [cottage] é inteiramente apropriada, pois isso pode significar um bangalô pequeno. O caso é que, em muitos povoados franceses naquele período, as casas dos interioranos eram assim, mas isso não significa que eram nem bangalôs nem pobres barracos.xvi. (pp. 48-49).

No final das contas, Eco optou por casupole in pietra (pequena casa de pedra), omitindo os telhados de colmo, de modo a perder o mínimo de propriedades, de possibilidades interpretativas fornecidas pelo francês.

Por vezes, aderir muito firmemente a um texto implica perdas irreparáveis; nesses casos, o autor indica uma reescrita moderada. (p. 57) Considera as reescritas não-moderadas (o que nos lembra das transcriações dos irmãos Campos e de Donaldo Schüler) dignas de nota como obras de arte, mas não como traduções:

"Inclino-me a excluir a reescrita das categorias das traduções porque não há dúvida de que seja um caso anômalo de tradução propriamente dita, que cai na categoria das interpretações intrasistêmicas, apenas à medida que a reescrita poética é admitida dentro da mesma língua. Em casos como esse, a reescrita pode até ser ampliada para incluir a paródia ${ }^{\text {xii }}$." (p. 106)

Interpretações intrasistêmicas, para Eco, são aquelas cujos interpretantes ${ }^{x v i i i}$ "pertencem ao mesmo sistema semiótico da expressão interpretada (a mesma forma da expressão) ${ }^{\text {xix } " ~(p . ~ 100) . ~ P o d e m ~ s e r ~}$ intralingüísticas, intersemióticas ou de execução (performance) (essa última aplica-se, por exemplo, ao caso de execuções de uma mesma música ou de um mesmo balé: mesmo que se siga uma partitura precisamente, a simples mudança de tom já faz com que a música seja outra, embora as notas permaneçam. No caso do balé, permaneceria a coreografia, mas mudar-se-ia, por exemplo, a velocidade dos movimentos, etc.). Em contrapartida à interpretação intrasistêmica figura a intersistêmica, que apresenta variação acentuada da substância; é o caso da tradução propriamente dita de Roman Jakobson ${ }^{\mathrm{xx}}$ (interlingual), da reescritura e da tradução intersemiótica. A reescrita é certamente um caso de interpretação; porém, somente é tradução se tem a pretensão de transmitir o 'espírito condutor' (seja qual for o significado disso, provavelmente seguindo a esteira das intentiones) do "original”, e não sua letra (p. 117).

Conforme Susan Bassnett quis incluir a literatura comparada nos estudos de tradução, Eco inclui a tradução na interpretação, que, sendo tomada em seu sentido mais amplo, contém a tradução interlingüística como um tipo muito limitado de interpretação (p. 76). Exemplifica: uma versão de dez páginas de David Copperfield escrita em italiano não pode ser considerada uma tradução, mas poderia se encaixar dentro de "interpretação". A tradução é "uma espécie do gênero interpretação, governada por certos princípios próprios à $\operatorname{tradução}{ }^{\text {xii } " . ~(p . ~ 80) ~}$ 
Com o que foi exposto acima, tivemos como objetivo explicitar a relação indissolúvel entre tradução e interpretação. Visto que um texto traduzido é interpretado e sempre sofre alterações, por mínimas que sejam, o mesmo é, ipso facto, levado ao leitor que o recebe com essas alterações - uma questão de recepção. Esperamos que tenha ficado claro, com essa breve exposição, o quanto os escritos de Umberto Eco são valiosos para os estudos de tradução, visto que são reflexões amparadas em diversas áreas, bem-fundamentadas e que abrangem todas as camadas, da mais rasa à mais profunda, do processo tradutório.

\section{REFERÊNCIAS BIBLIOGRÁFICAS}

COMPAGNON, Antoine. O demônio da teoria: literatura e senso comum. Belo horizonte: Ed. UFMG, 2001. ECO, Umberto. Os limites da interpretação. São Paulo: Perspectiva, 2000. $2001 \mathrm{a}$. Superinterpretando textos. In Interpretação e superinterpretação. São Paulo: Martins Fontes,

Experiences in translation. Toronto: Toronto University Press, $2001 \mathrm{~b}$.

Obra aberta. São Paulo: Perspectiva, 2003a.

Sobre a literatura - ensaios. Rio de Janeiro: Record, 2003b.

Lector in fabula. São Paulo: Perspectiva, 2004.

JAKOBSON, Roman. Aspectos lingüísticos da tradução. In: Cultrix, 1974, p. 65.

MITTMANN, Solange. Notas do tradutor e processo tradutório: análise sob o ponto de vista discursivo. Porto Alegre, Ed. da UFRGS, 2003.

STEINER, George. After Babel: aspects of language \& translation. Oxford: Oxford University Press, 1992, 2nd edition.

Notas:

i Para um excelente levantamento dessas tais orientações, conferir o capítulo The claims of theory, em STEINER, George. After Babel: aspects of language \& translation. Oxford: Oxford University Press, 1992, $2^{\text {nd }}$ edition.

${ }^{\text {ii }}$ MITTMANN, Solange. Notas do tradutor e processo tradutório: análise sob o ponto de vista discursivo. Porto Alegre, Ed. da UFRGS, 2003.

iii ECO, Umberto. Obra aberta. São Paulo: Perspectiva, 2003a.

iv ECO, Umberto. Lector in fabula. São Paulo: Perspectiva, 2004.

${ }^{v}$ ECO, Umberto. Os limites da interpretação. São Paulo: Perspectiva, 2000.

${ }^{\mathrm{vi}}$ ECO, Umberto. Sobre a literatura - ensaios. Rio de Janeiro: Record, 2003b.

vii COMPAGNON, Antoine. O demônio da teoria: literatura e senso comum. Belo horizonte: Ed. UFMG, 2001.

viii ECO, Umberto. Superinterpretando textos. In: __. Interpretação e superinterpretação. São Paulo: Martins Fontes, 2001a.

${ }^{i x}$ ECO, Umberto. Experiences in translation. Toronto: Toronto University Press, $2001 \mathrm{~b}$.

$x$ "What is a 'sense' that does not correspond to the literal meaning? Does such a sense depend on the lexical meaning of the single words or on the meaning of a sentence?"

xi "The word connotation is an umbrella term used to name many, many kinds of non-literal senses of a word, of a sentence, or of a whole text. That words, sentences, and texts usually convey more than their literal sense is a commonly accepted phenomenon, but the problems are (i) how many secondary senses can be conveyed by a linguistic expression, and (ii) which ones a translation should preserve at all costs."

xii "Similarity in meaning can only be established by interpretation, and translation is a special case of interpretation (...)".

xiii "Translations are not about linguistic types but rather about linguistic tokens. Translations do not concern a comparison between two languages but the interpretation of two texts in two different languages."

xiv "Interpreting means making a bet on the sense of a text, among other things."

${ }^{x v}$ It is clear that every single text allows for a different and individual solution. Common sense suggests that in The Island of the Day Before translators can change 'Roberto saw a striped polyp' into 'Roberto saw an ocellated polyp', but they certainly are not permitted to change the global macro-proposition 'Roberto is shipwrecked on an abandoned vessel just off an island that lies beyond the $180^{\text {th }}$ meridian.

A first hypothesis is that one can change the literal meaning of single sentences in order to preserve the meaning of the corresponding micropropositions, but not the sense of major macro-propositions. But what about many intermediate 'shallow' stories (between the literal meaning of single sentences and the global sense of an entire novel)? One could decide, for example, that if character A tells a long stupid joke and if no literal translation can render the stupidity of that joke, a translator is entitled to switch to another joke, provided it remains clear that A tells silly jokes. It is on the basis of interpretative decisions of this kind that translators play the game of faithfulness."

xvi "Now, the French term expresses at least five properties: a chaumière is (i) a peasant's house, (ii) small, (iii) usually made of stone, (iv) with a thatched roof, (v) humble. It's impossible to say it in Italian in only one word, especially if one has to add, as happens in chapter 6, that the aunt's petite chaumière was 'en pietres de grès inegales'. This is not a capanna, which in Italian suggests a wooden structure. It is not a casetta because it has a thatched roof (while the Italian casetta has a tiled roof, and is not necessarily a poor dwelling), but neither is it a baita, which is a crude construction found in the mountains, a temporary refuge. I fell that not even a cottage is entirely appropriate, because this might mean a small bungalow. The fact is that in many French villages in that period the houses of the country folk were like that, but this does not mean they were either bungalows or wretched shacks."

xvii "I would tend to exclude rewriting from the ranks of translations because there is no doubt that it is an anomalous case of translation proper, which falls into the category of intrasystemic interpretations, only insofar as poetic rewriting is admitted within the same language. In such cases, rewriting may even be stretched to include parody." 
xviii Segue a definição de interpretante, segundo Pierce: "Um signo, ou representâmen, é alguma coisa que está para alguém em lugar de alguma coisa em qualquer relação ou capacidade. Isso se endereça a alguém, ou seja, cria na mente daquela pessoa um signo equivalente ou talvez um signo mais desenvolvido. O signo que é criado eu o chamo de interpretante do primeiro signo. Este signo está para alguma coisa, o próprio objeto. Ele está para aquele objeto, não sob todos os aspectos, mas com referência a uma espécie de idéia, que então chamei de ground da interpretação. Citado em ECO, 2004, p. 14.

xix "The interpretants belong to the same semiotic system as the interpreted expression (the same form of the expression)".

xx JAKOBSON, Roman. "Aspectos lingüísticos da tradução”. In: __. Lingüística e comunicação. São Paulo: Editora Cultrix, 1974, p. 65.

xxi “(...) species of the genus interpretation, governed by certain principles proper to translation”. 